\title{
Interdependence of flows when merge in rail tunnel evacuations
}

\author{
Adriana Balboa, Daniel Alvear, Orlando Abreu \\ University of Cantabria \\ Los Castros s/n, Santander, Spain \\ balboaa@unican.es; alveard@unican.es; abreuo@unican.es
}

\begin{abstract}
The understanding of merging flows during evacuation can have important implications for rail tunnels safety. This paper explores the interdependence of the merging of flows coming from the walkway with those exiting the train. Eight train exit configurations were tested using a mock-up of a rail car exit and a lateral walkway involving 77 participants (mean age 48; standard deviation 15; range 18-74). New measurements and data processing methods are proposed allowing statistical analysis to be performed. The results provide quantitative evidence of the preferences between flows. We found that the bias in the evacuation was slightly in favour of the walkway when train exit was at $0 \mathrm{~m}$ in height. Contrary to expectations a moderate dominance of walkway flow was observed at $0.8 \mathrm{~m}$ in height. Less variation was found for the train exit at $1.2 \mathrm{~m}$ in height with a clear priority of walkway flow. This happened despite deference behaviours performed by participants, i.e. people stopped to help those entering from the rail car. This novel contribution aims to provide a new method for those involved in development and validation of new and current evacuation modelling tools and those who want to improve their understanding of merging behaviour during evacuation in rail tunnels.
\end{abstract}

Keywords: Merging flows, evacuation, experimental data set, rail tunnels.

\section{Introduction}

Emergency evacuations of rail vehicles (trains, metro) inside tunnels are complex processes. Rail tunnels are unique environments with their own specific characteristics such as long evacuation distances and lateral walkways with no natural light [1]. These characteristics may increase the risk to passengers in case of evacuation since the available time to escape can be short. In such conditions, an appropriate design and an effective evacuation strategy can save lives. In this sense, computer modelling permits rail tunnel evacuation to be evaluated. This involves advantages such as the reduction of the actual trials and the increase of the number of scenarios in the analysis.

Simulation models can provide consistent and accurate results when reliable inputs are used $[2,3]$. The potential of such analyses is clear $[4,5,6,7]$. Nevertheless, data on rail evacuation is scarce. Some references in the literature describe the performance of evacuees in rail tunnels including train exit flow rates $[8,9,10,11]$, walking speeds under smoke conditions $[12,13]$ and on a tunnel walkway [14] and even exit strategies adopted by people to overcome the height of train exits [10].

However, less attention has been paid to merging conditions between rail car exits and the walkway and, therefore, very little is still known about this process. As suggested by [8], there is a need to determine the cause and effect relationship between the population density inside the tunnel and the flow rate capacity of a train exit, as this is expected to have a significant influence on the total evacuation time.

This paper aims to contribute to the existing body of work by analysing the merging process and how this impacts evacuation in rail tunnels. The main scope is to provide rail operators, authorities, researchers, engineers, designers, model developers and model users with a method to determine the interdependence of flows when merging to better understand this process and its impact on life safety. 


\section{Method}

The proposed method is applied to evacuation experiments conducted in an indoor sports court at the University of Cantabria (Spain). A full-scale mock-up was used representing a train exit and a lateral walkway (see Figures 1 and 2). It was built flexible enough to change the height of the train exit area $(h)$ and width $\left(w_{t}\right)$ as well as the walkway width $\left(w_{w}\right)$. As Table 1 shows, eight exit configurations were analysed involving 16 trials.

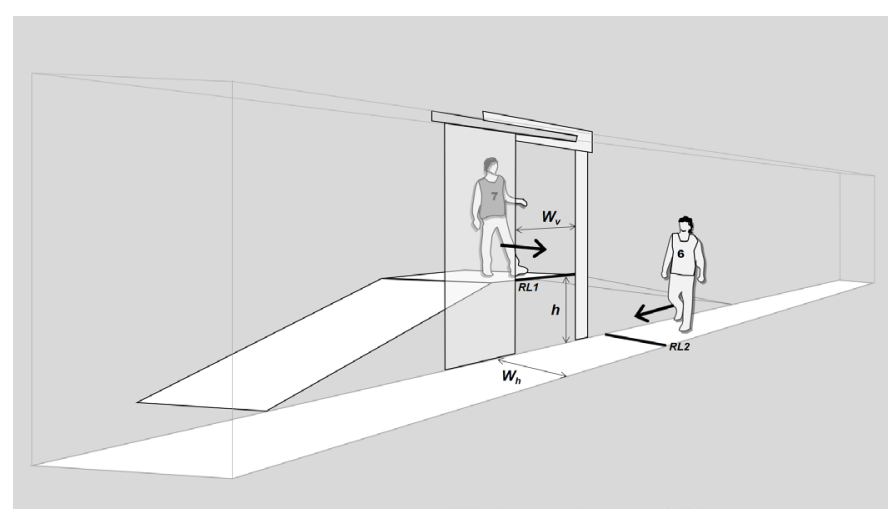

Fig. 1. Experimental mock-up.

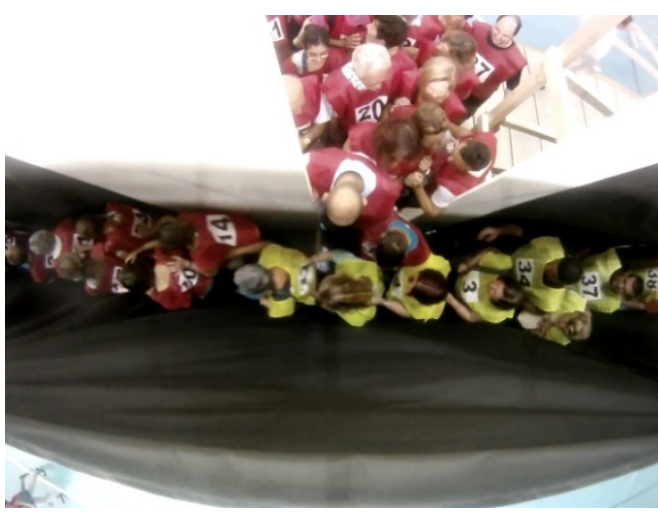

Fig. 2. Layout and participants during a trial.

Table 1: Characteristics of trials conducted.

\begin{tabular}{|c|c|c|c|c|c|}
\hline \multirow{2}{*}{ Test } & \multicolumn{2}{|c|}{ Initial location } & \multicolumn{3}{c|}{ Variable of interest } \\
\cline { 2 - 6 } & Red group & Yellow group & $h(\mathrm{~m})$ & $w_{t}(\mathrm{~m})$ & $w_{w}(\mathrm{~m})$ \\
\hline 1 & Rail car & Walkway & 0 & 0.8 & 1.2 \\
\hline 2 & Walkway & Rail car & 0 & 0.8 & 1.2 \\
\hline 3 & Rail car & Walkway & 0 & 1.2 & 1.2 \\
\hline 4 & Walkway & Rail car & 0 & 1.2 & 1.2 \\
\hline 5 & Walkway & Rail car & 0 & 0.8 & 0.8 \\
\hline 6 & Rail car & Walkway & 0 & 0.8 & 0.8 \\
\hline 7 & Walkway & Rail car & 0 & 1.2 & 0.8 \\
\hline 8 & Rail car & Walkway & 0 & 1.2 & 0.8 \\
\hline 9 & Rail car & Walkway & 0.8 & 0.8 & 0.8 \\
\hline 10 & Walkway & Rail car & 0.8 & 0.8 & 0.8 \\
\hline 11 & Rail car & Walkway & 0.8 & 0.8 & 1.2 \\
\hline 12 & Walkway & Rail car & 0.8 & 0.8 & 1.2 \\
\hline 13 & Walkway & Rail car & 1.2 & 1.2 & 1.2 \\
\hline 14 & Rail car & Walkway & 1.2 & 1.2 & 1.2 \\
\hline 15 & Walkway & Rail car & 1.2 & 1.2 & 0.8 \\
\hline 16 & Rail car & Walkway & 1.2 & 1.2 & 0.8 \\
\hline
\end{tabular}

In total 77 participants were used. A deliberate recruitment process was conducted to meet future passenger demographics ${ }^{1}$. Therefore, ageing population was selected (mean age 48; standard deviation 15; range 18-74) with $48 \%$ female and $52 \%$ male. No children were allowed. Participants were asked to carry backpacks $(21 \%)$ or handbags $(62 \%)$.

Participants signed a Consent Informed Form before the experiment. They were randomly divided into two groups: red group (39) and yellow group (38). One group was initially located on the train and another group formed a queue at the entrance of the walkway. A whistle was then used to start the trial. The trial finished when the last participant left the walkway. The initial location of the groups was switched for the next trial.

\footnotetext{
${ }^{1}$ Eurostat population projections: http://ec.europa.eu/eurostat/statistics-explained/index.php/People in the EU \%E2\%80\%93 population projections
} 
Video cameras were placed at the top of the walkway to gain an overhead view of the merging area (see Figure 2). Video recordings, collected at a frequency of 29.97 frames/s, were manually analysed using an image processing software. The specific frame when the body of each participant crossed a reference line (for both participants from the train exit and walking through the walkway) was noted and then transcribed into a spreadsheet. The reference lines were the rail car exit and a line on the walkway floor located $0.6 \mathrm{~m}$ before the rail car exit. A new variable was considered namely the instantaneous specific flow $\left(\widehat{F}_{S}\right)$ defined as the time interval between two participants, coming from the same location train or walkway, that cross a reference line divided by its effective width:

$$
\hat{F}_{S}=\frac{1}{\Delta t_{i, i-1} * w_{e f}}
$$

Where $\Delta t_{i, i-1}$ is the time interval between an individual and the next one who crosses a reference line and $w_{e f}$ is the effective width. This new variable can be easily derived from the measured time intervals. The advantage is the possibility to produce statistical samples instead of using constant values. It is important to note that the use of flow rates (constant values) tends to average the personal hesitations leading to a simple representation of the actual passenger rail car exit flow [15]. Therefore, passengers' exiting processes could be considered as a random variable that depends on passengers (abilities, behaviour, baggage, etc.), design (exit, walkway) and how they behave in response to it [16]. Nevertheless, care should be taken when using the proposed measurements. Very short time intervals between two subjects produce higher values (i.e. outliers). There are methods for the extreme values (lower and upper bound) definition and elimination of outliers to deal with this problem. Data samples of time spent by each participant to cross a line of reference are likely to be skewed [15], being necessary to calculate the medcouple, which is a robust measure of skewness introducing a correction to the Tukey Test [17].

The aim of the proposed method is to determine the interdependence between flows when merging. This involves the assumption that the flow from the train and the flow from the walkway are related and mutually dependent. In total 32 independent samples of instantaneous specific flow during the merging process were collected. The samples from the train exit and the walkway derived from the same trial were combined keeping the original order of access to the merging area. A novel way of data clustering was applied to explore the interdependence of flows when merging In Clustering A, clusters were defined as groups of participants interacting each other. In Clustering B, clusters were defined as time intervals during the merging period. Since clustering is not an automatic task but an iterative process, we selected different groups of participants for Clustering A (6,8 and 10 participants) and for Clustering B we selected different time intervals $(5,7.5$ and $10 \mathrm{~s})$. The mean value of the instantaneous specific flows was calculated separately and paired samples (train - walkway) were obtained for each cluster. The data points of the means were then plotted according to the height differential of the train exit. This allowed us to explore the mutual relationship between flows produced in the three different evacuation conditions (train exit height of $0,0.8$ and $1.2 \mathrm{~m}$ ). Finally, a least-square linear regression through the origin was employed to represent the interdependence of flows [18].

\section{Results}

Figure 3 shows the interdependence of flows when merging process occurs for Clustering A and Figure 4 shows the results produced by Clustering B. The $\mathrm{x}$-axis corresponds to the walkway flow and $y$-axis corresponds to train exit flow. The straight line in the figures is the reference line, with a slope equal 1, used to show no reciprocal influence between flows (i.e. it represents a 50:50 merging ratio). The slopes of the lines illustrate the interrelation between both flows. Although results varied among clusters, the same pattern was found. Some previous studies detected differences in merging for several configurations at the same height [19]. We found that height conditions that represent evacuation in rail tunnels also have impact on merging process. As Figures 3 and 4 shows, all regression lines (dashed 
lines) were below the reference line (straight line) denoting a walkway priority. However, this priority varied according to the height of the train exit.

From the Figures 3 and 4 it is possible to see a slight priority of walkway flow over the train flow (slope lines 0.87-0.97) with no height differential of the train exit $(\mathrm{h}=0 \mathrm{~m})$. The slope lines when $\mathrm{h}=0.8$ $\mathrm{m}$ (Clustering A 0.79-0.92 and Clustering B 0.81-0.84) suggests a moderate dominance of walkway flow over the train exit flow. However, a clear priority of the walkway flow was found when $\mathrm{h}=1.2 \mathrm{~m}$ denoted by the low values of the slope lines (0.53- 0.65 and 0.53-0.63 in Clustering A and B respectively). It is apparent from results in Figures 3 and 4 that the higher the height differential of the rail car exit, the more dominance of the walkway flow.

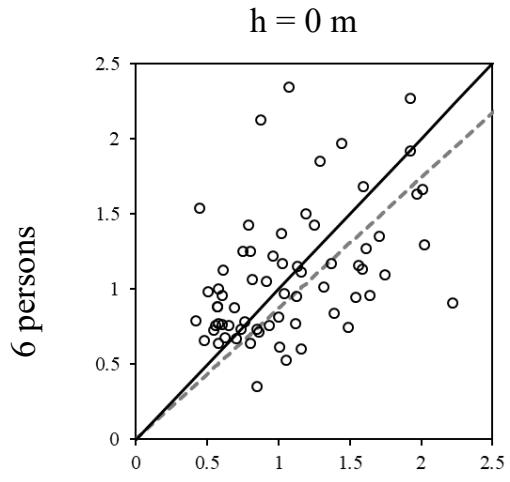

Slope regression line: 0.87

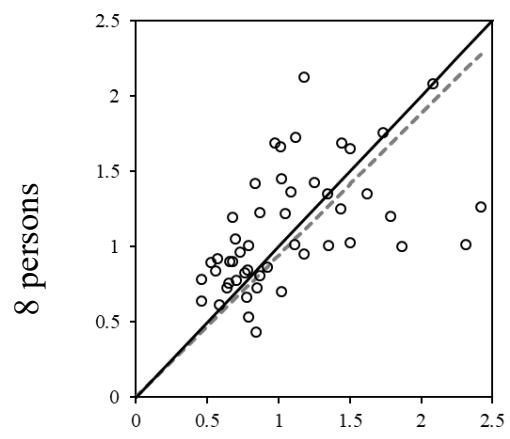

Slope regression line: 0.94

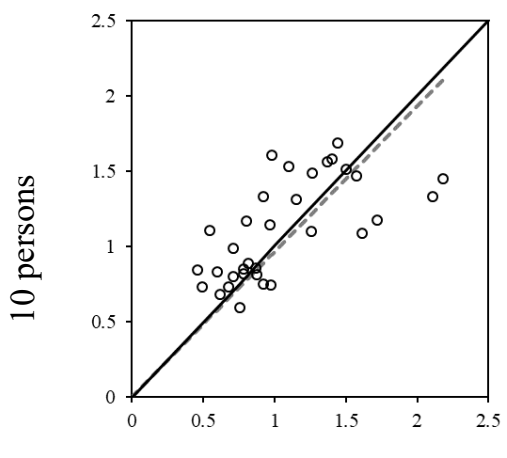

Slope regression line: 0.97

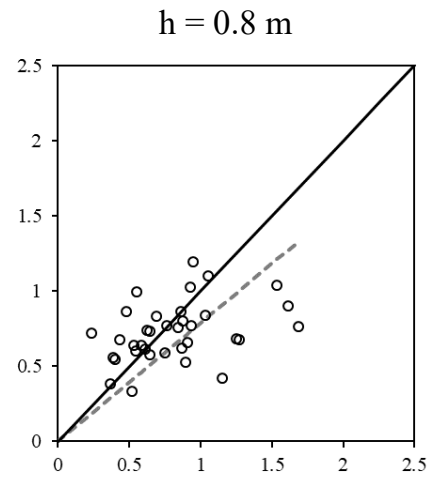

Slope regression line: 0.79

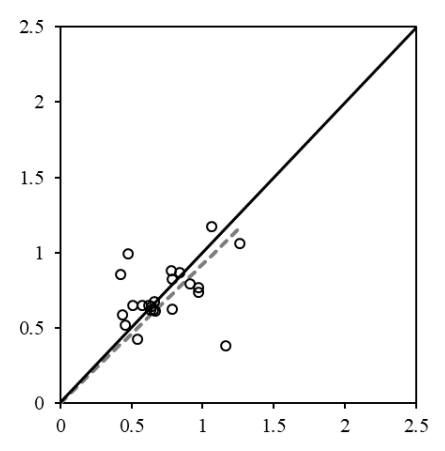

Slope regression line: 0.92

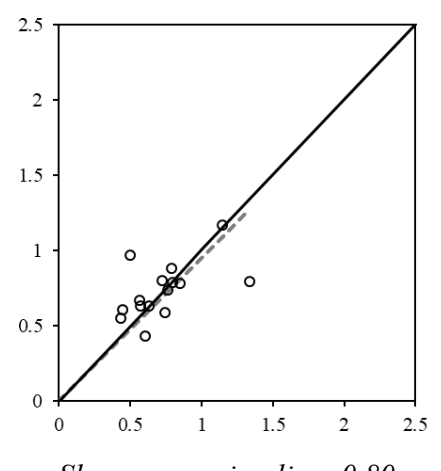

Slope regression line: 0.80

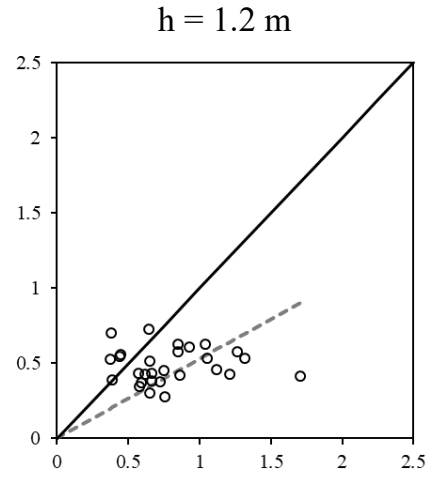

Slope regression line: 0.53

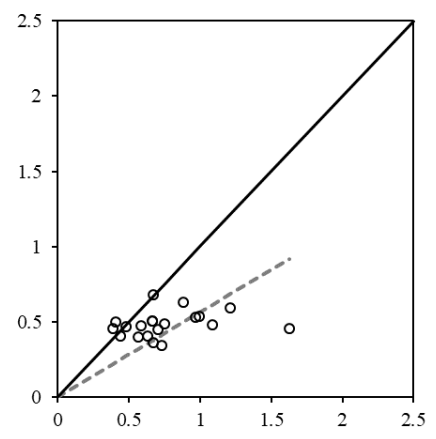

Slope regression line: 0.56

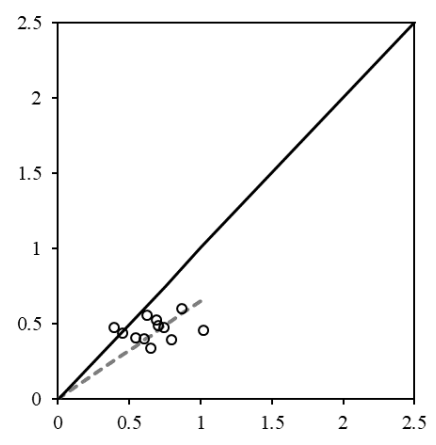

Slope regression line: 0.65

-.-. Regression lines

— Reference lines (merging ratio 50:50)

Fig. 3. Clustering A. Interdependence between walkway flow (x-axis)-train exit flow (y-axis) in [per/s m]. 


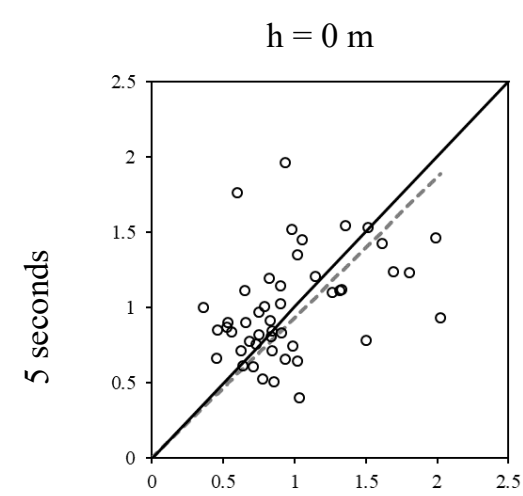

Slope regression line: 0.93

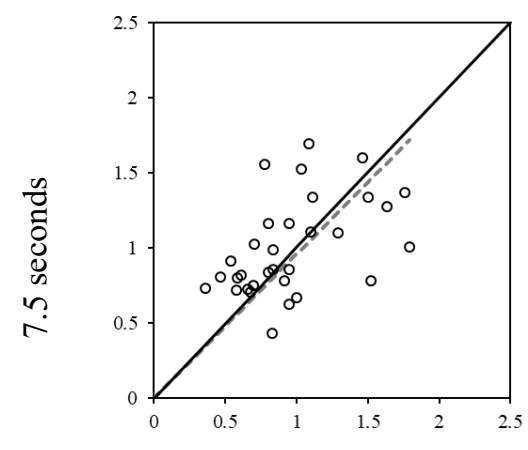

Slope regression line: 0.96

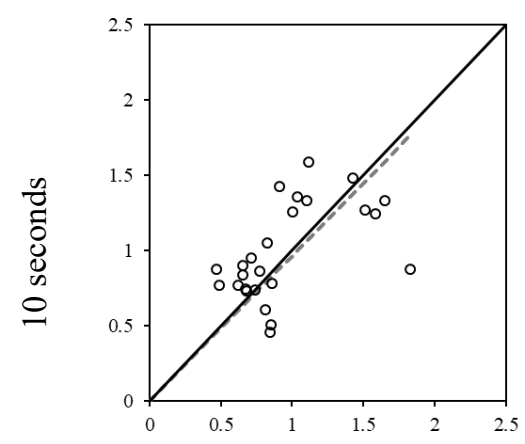

Slope regression line: 0.96

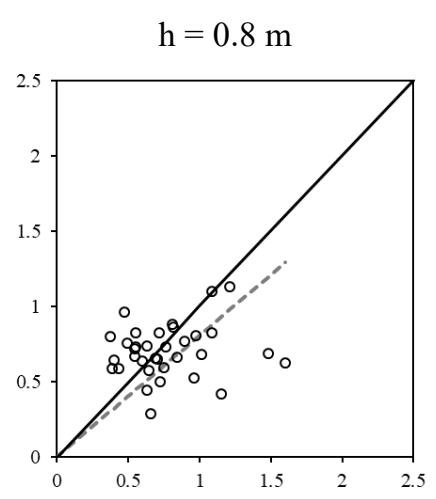

Slope regression line: 0.81

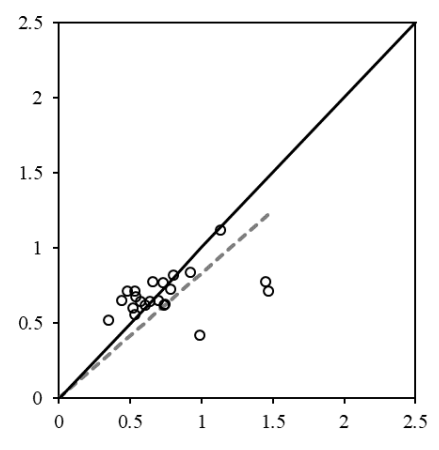

Slope regression line: 0.83

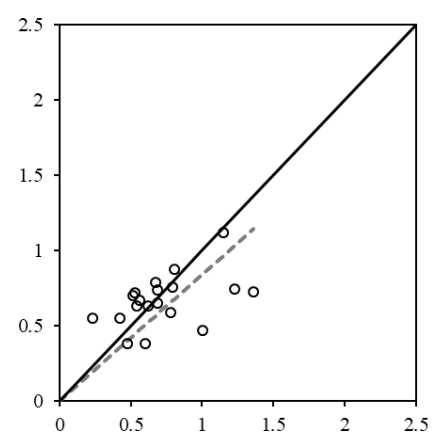

Slope regression line: 0.84

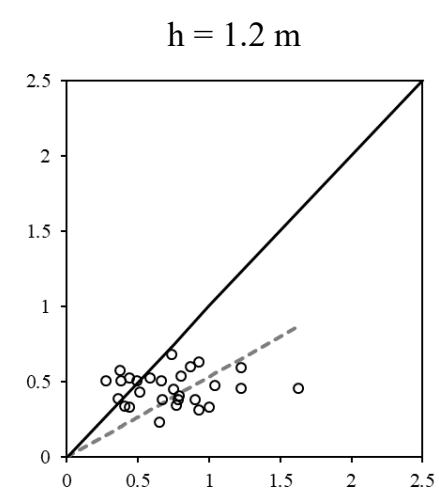

Slope regression line: 0.53

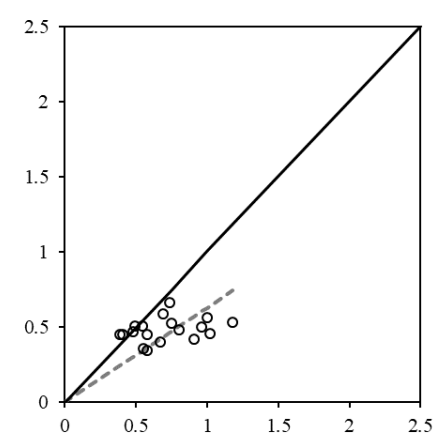

Slope regression line: 0.63

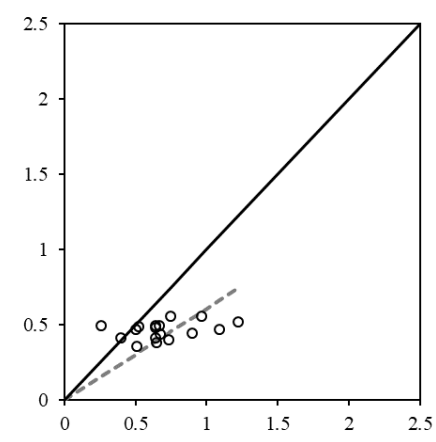

Slope regression line: 0.61

--.- Regression lines

— Reference lines (merging ratio 50:50)

Fig. 4. Clustering B. Interdependence between walkway flow (x-axis)-train exit flow (y-axis) in [per/s m].

\section{Discussion}

In reviewing the literature, no data was found on the interaction between the flow from those coming from the walkway and the flow from those exiting the train in rail tunnel evacuations. This paper proposes a way to determine the interdependence between such flows. Datasets from rail car evacuation experiments were analysed. The experiments were conducted in a mock-up of a rail car exit and a lateral walkway allowing eight train exit configurations to be analysed. A representative sample of future rail 
transport population was used. New measurements were proposed to obtain random flow samples for the statistical analysis. The idea behind the presented analysis is that merging flows are mutually dependent.

Paired samples of the mean values derived from both flows were compared through a linear regression analysis. Three different train exit conditions were examined depending on the height differential of the train exit: no height differential, $0.8 \mathrm{~m}$ and $1.2 \mathrm{~m}$. With no height differential, a balance between merging flows was observed (i.e. train participants and walkway participants almost equally accessed to the merging area). With higher height differential $(0.8 \mathrm{~m}$ and $1.2 \mathrm{~m})$ walkway participants were observed performing deference behaviours such as reducing their walking speed, waiting until they had enough space to access the merging area and/or stopping to help those entering from the rail car (i.e. given their hands and/or using their bodies as support). Despite these observations, our findings confirm a walkway flow priority over the train flow.

These findings may have important implications for rail tunnels design and the definition of appropriate evacuation procedures. In general, there is a lack of homogeneity in evacuation design requirements for rail tunnels. For instance, the minimum lateral walkway width recommended ranges from $0.80 \mathrm{~m} \mathrm{[20]} \mathrm{to} 1.45 \mathrm{~m}$ [21]. There is also a lack of detail in some other requirements such as the height between the train floor and the walkway, barely suggested or omitted. Results suggest a walkway as high as the train floor to facilitate an effective evacuation from rail vehicles even when merging occurs. It is important to note that, some participants (by $7.69 \%$ and $26.32 \%$ of participants for $\mathrm{h}=0.8 \mathrm{~m}$ and $\mathrm{h}=$ $1.2 \mathrm{~m}$ respectively) decided to withdraw because of the rail car exit height. A key aspect is the availability of sufficiently detailed, comprehensive and relevant data to analyse the impact of merging process on different evacuation strategies. It should be mentioned that evacuation models are now requiring distributions to produce probabilities of outcomes [5]. In fact, current evacuation models for passenger trains use distributions to represent the exiting performances of passengers $[2,3,15]$. Our research supports this by the use of a new random variable (the instantaneous specific flow) derived from a straightforward measurement method. It is argued that results produced can be used as a reference to conduct a more detailed analysis by using evacuation modelling. For instance, a model user could configure the model by implementing the relation of dependence between the merging flows and explore different evacuation strategies (i.e. number of exits available to reduce the merging points, giving priority to the passengers that are closer to the fire, etc.).

Although this paper can provide some support for further analyses, caution must be applied as the findings may not be generalized. Despite the mock-up was flexible enough to reproduce different exit configurations, different factors were not present during the experiment (i.e. visibility conditions, collective behaviours, crew procedures, etc.). Future work, which takes these factors into account, will need to be undertaken preferably in real tunnel environments.

\section{Acknowledgements}

The authors would like to thank the Ministry of Economy, Industry and Competitiveness (MINECO) for funding the SIGNAL project on the frame of the Subprogram RETOS-COLABORACIÓN 2016 call (Ref -RTC-2016-5474-4) as well as the European Union through ERDF funding under the objective of Strengthening Research, Technological Development and Innovation.

\section{References}

[1] E. Ronchi, P. Colonna, J. Capote, D. Alvear, N. Berloco, and A. Cuesta, "The evaluation of different evacuation models for assessing road tunnel safety analysis", Tunnelling and Underground Space Technology, vol. 30, pp. 74-84, 2012.

[2] J. Capote, D. Alvear, O. Abreu, and A. Cuesta, "Analysis of evacuation procedures in high speed train fires”, Fire Safety Journal, vol. 49, pp. 35-46, 2012a. 
[3] J. Capote, D. Alvear, O. Abreu, A. Cuesta and V. Alonso, "A stochastic approach for simulation human behavior during evacuation process in passenger trains", Fire Technology, vol. 48, pp. 911-925, 2012b.

[4] A. Cuesta, D. Alvear, O. Abreu, and D. Silió, "Real-time stochastic evacuation models for decision support in actual emergencies", in IAFSS Fire Safety Science, New Zealand, 2014, vol. 11, pp. 1063-1076.

[5] A. Cuesta, O. Abreu, and D. Alvear, "Future challenges in evacuation modelling", in Evacuation Modeling Trends, Ed. Springer International Publishing, 2016, pp. 103-129.

[6] W. L. Wang and T. Y. Jacqueline Lo, “A Simulation Study on Passenger Escape in Rail Tunnels", Procedia Engineering, vol. 71, pp. 552-557, 2014.

[7] B. V. Weyenberge and X. Deckers, "Development of a risk assessment method for fire in rail tunnels", in the $7^{\text {th }}$ International Conference Tunnel Safety and Ventilation, Graz, 2014, pp. 180-189.

[8] K. Fridolf, D. Nilsson and H. Frantzich, "The flow rate of people during train evacuation in rail tunnels: Effects of different train exit configurations", Safety Science, vol. 62, pp. 515-529, 2014a.

[9] K. Fridolf, D. Nilsson and H. Frantzich, "Evacuation of a Metro Train in an Underground Rail Transportation System: Flow Rate Capacity of Train Exits, Tunnel Walking Speeds and Exit Choice", Fire Technology, vol. 52, pp. 1481-1518, 2016.

[10] M. Oswald, H. Kirchberger and C. Lebeda, "Evacuation of a high floor metro train in a tunnel situation: experimental findings", in Fourth International Conference on Pedestrian and Evacuation Dynamics, PED 2008, Springer, University of Wuppertal, Germany, 2008, pp. 67-81.

[11] A. Norén, and J. Winér, "Modelling Crowd Evacuation from Road and Train Tunnels-Data and design for faster evacuations", Report 5127, Dept. of Fire Safety Engineering, Lund University, Sweden.

[12] M. Seike, N. Kawabata and M. Hasegawa, "Experiments of evacuation speed in smoke-filled tunnel”, Tunnelling and Underground Space Technology, vol. 53, pp. 61-67, 2016.

[13] H. Frantzich and D. Nilsson, "Evacuation experiments in a smoke filled tunnel", in Proceedings of 3rd International Symposium Human Behaviour in Fire, Belfast, United Kingdom, 2004, pp. 229238.

[14] V. Lundström, J. Ahlfont and D. Nilsson, "The effect of raised walkway design on evacuation behaviour in rail tunnels", in IAFSS Fire Safety Science, New Zealand, 2014, vol. 11, pp. 1091-1102.

[15] E. R. Galea, D. Blackshields, K. M. Finney and D. P. Cooney, "Passenger Train Emergency Systems: Development of Prototype railEXODUS Software for U.S. Passenger Rail Car Egress", Final Report, U.S. Department of Transportation Federal Railroad Administration.

[16] S. Gwynne, E. Kuligowski, J. Kratchman and J. A. Milke, "Questioning the linear relationship between doorway width and achievable flow rate", Fire Safety Journal, vol. 44, pp. 80-87, 2009.

[17] J. W. Tukey, Exploratory Data Analysis. Reading (Addison-Wesley), Massachusetts, 1977.

[18] J. G. Eisenhauer, "Regression through the Origin", Teaching Statistics, vol. 25, pp. 76 - 80, 2003.

[19] L. Lian, X. Mai, W. Song, Y. K. K. Richard, Y. Rui and S. Jin, "Pedestrian merging behavior analysis: An experimental study”, Fire Safety Journal, vol. 91, pp. 918-925, 2017.

[20] European Commission, "Concerning the technical specification for interoperability relating to 'safety in railway tunnels' of the rail system of the European Union", Official Journal of the European Union, Commission Regulation (EU), no. 1303/2014, 2014.

[21] Fire in Tunnels, "Fire Safe Design-Rail Tunnels", European Thematic Network Fire in Tunnels, Technical report part 2. [Online]. Available: 
Proceedings from the 9th International Conference on Pedestrian and Evacuation Dynamics (PED2018) Lund, Sweden - August 21-23, 2018

https://www.iroads.co.il/sites/default/files/imce/fit - fire in tunnels - part 2.pdf 